\title{
Synthesis of Efavirenz via Asymmetric Alkynylation
}
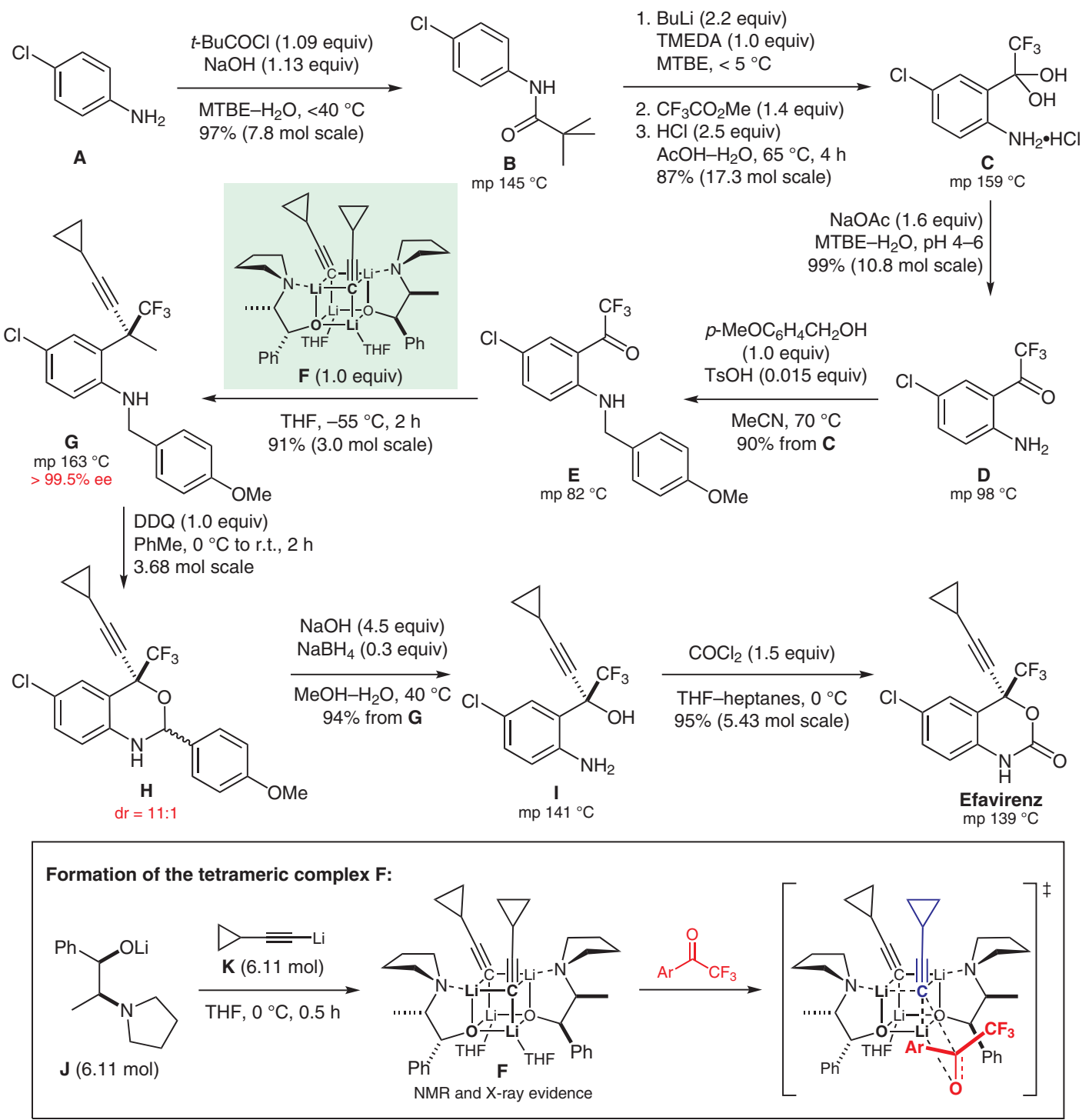

Significance: Efavirenz (Sustiva ${ }^{\circledR}$ ) is an HIV-1 reverse transcriptase inhibitor that was approved by the FDA in 1998 for the treatment of HIV/AIDS. The classic DuPont-Merck synthesis depicted incorporates a highly enantioselective addition of lithium acetylide $\mathbf{K}$ (as the tetrameric complex $\mathbf{F}$ ) to ketone E mediated by chiral chaperone J. The synthesis proceeds in $62 \%$ overall yield in just seven steps. Since all intermediates were crystalline, no chromatography was required.

\section{Category}

Synthesis of Natural

Products and

Potential Drugs

\section{Key words}

efavirenz

reverse

transcriptase

inhibitor

asymmetric alkynylation

chiral chaperone
Comment: For the mechanism of the acetylide addition, see: A. Thompson et al. J. Am. Chem. Soc. 1998, 120, 2028. For further practical refinements in the nucleophilic addition, see: A. Choudhury et al. Org. Process Res. Dev. 2003, 7, 324. A large scale enantioselective alkynylation of ketone $\mathbf{D}$ mediated by chiral chaperone J gave adduct I directly in 95\% yield (er > 99:1) on a $4.5 \mathrm{~mol}$ scale: WO 1998 51676. 